Locating mathematics within post-16 vocational education in England D. Dalby and A. Noyes

School of Education, University of Nottingham, Nottingham, England

Diane Dalby (corresponding author)

School of Education

University of Nottingham

Jubilee Campus

Wollaton Road

Nottingham

NG8 1BB

01157484392

diane.dalby@nottingham.ac.uk

Andrew Noyes

School of Education

University of Nottingham

Jubilee Campus

Wollaton Road

Nottingham

NG8 1BB

01159514470

andrew.noyes@nottingham.ac.uk 


\section{Locating mathematics within post-16 vocational education in England}

The political importance of mathematics in post-16 education is clear. Far less clear is how mathematics does and should relate to vocational education. Successive mathematics curricula (e.g. core skills, Key Skills) have been developed in England with vocational learners in mind. Meanwhile, general mathematics qualifications remain largely disconnected from vocational learning. Following a brief historical survey of mathematics within vocational education, the paper presents findings from a nested case study of student groups in three large Further Education colleges in England. The primary unit of analysis herein is student groups learning Functional Mathematics in two vocational areas: construction and hairdressing. We show how approaches to organising teaching, developing connected curricula and classroom pedagogy tend to isolate or integrate mathematics from/with the vocational experience. Integrated approaches are shown to impact positively on student engagement and attitudes to learning mathematics. The paper concludes by discussing the potential impact of academic qualifications displacing vocationally-relevant mathematics.

Keywords: vocational; mathematics; Functional Mathematics; Further Education.

\section{Background}

Mathematics education in England is arguably subject to greater political and media scrutiny than any other subject. This is due to its importance to a number of key stakeholder groups, the growing influence of international league tables and, ultimately, its influence on individual and collective economic productivity. Research shows that greater mathematical competence in school is associated with higher earnings (Crawford \& Cribb, 2013) and, conversely, that low levels of numeracy are a stronger predictor of unemployment than low levels of literacy (Parsons \& Bynner, 2005).

Although there is widespread agreement on the need for improvement in mathematics learning and qualifications, the tasks of defining 'better' mathematics education, particularly for vocational students, and realising improvements at scale are far more complex. In this paper we focus on a relatively neglected area of post-16 mathematics 
education, namely the experiences of learners aged 16-18 years on vocational courses in Further Education (FE) settings. In England, 16-year-olds complete General Certificate in Secondary Education (GCSE) in several subjects, including mathematics, before continuing either to further academic study or into vocational education, the majority of which is provided by Further Education (FE) colleges. The influential Wolf Report (Wolf, 2011) has resulted in all post-16 students without a grade $\mathrm{C}$ or above in GCSE Mathematics being required to re-sit this examination or be working towards an interim qualification such as Functional Mathematics ${ }^{\mathrm{i}}$. Recent figures indicate that $37 \%$ of the 2012/13 age 16 GCSE cohort did not achieve a grade C in mathematics (DfE, 2014) and that three-quarters of those students transferred to FE colleges (Education and Training Foundation, 2014): around 180,000 young people. The impact of these policy changes is therefore particularly significant for FE colleges.

Although other challenges arise for college management, (such as a shortage of suitably qualified teachers), our main concern here is how mathematics is positioned within the student learning experience. Students on vocational pathways often have low prior mathematical attainment and find the subject unappealing. Those with a history of failure are more demanding to teach (Turner, Harkin, \& Dawn, 2000) so, for a subject often associated with disaffection (City \& Guilds, 2012; Nardi \& Steward, 2003), strategies to engage students in meaningful learning experiences are important.

To understand this positioning of mathematics within the student experience, we also need to consider the context in which the subject is situated. Mathematics education within FE in England intertwines three areas of policy and practice: academic, vocational and adult education. These strands of the education system, each associated with different ideologies, traditions and socio-cultural practices, have distinct historical roots, leading to different views of mathematics. A deeply embedded 
academic-vocational division continues to have a considerable impact (Pring et al., 2009) and the positioning of mathematics within FE is characterised by tensions between contrasting views of the subject's value in relation to academic or vocational goals. In the academic pathway, mathematics is a core discipline with high status and exchange-value. It acts as the most powerful 'gatekeeper' (Volmink, 1994) to further study and future employment opportunities. The relationship between mathematics and vocational education has been more uncertain and this is examined further in the following section.

This paper explores how mathematics, in particular Functional Mathematics, is located within the experiences of FE students. Using the twin concepts of integration and isolation, which emerged as strong themes from the research, we describe contrasting locations of mathematics with respect to students' vocational learning and consider the impact of college policies enacted at different levels, particularly in terms of college structures, programme organisation, curriculum and pedagogy. Before we present our empirical findings, the following section outlines relevant historical developments and considers how these have framed mathematics policy and practice within FE colleges. Some recurring historical themes are introduced here that are key to the interpretation of our data.

\section{The historical positioning of mathematics in education}

As early as the eighteenth century, academic and vocational educations were distinguishable as separate strands. Schools provided the classical, liberal education favoured by English public schools and universities (Hyland, 1999) where knowledge had intrinsic value. Work-related training focussed on developing practical skills within the workplace through apprenticeships. These two pathways signalled the division 
between academic education and vocational training that has pervaded the English education system to this day, affecting 14-19 education policy (Young, 2011), curriculum and organisation (Hodgson \& Spours, 2008).

Mathematics education based on a classical Euclidean view became established in schools. It was only with the growth of technical education in the late nineteenth century through the Mechanics Institutes and early technical colleges (Hyland \& Merrill, 2003; Lucas, 2004), that new forms of applied science and mathematics learning emerged that could be described as general work-related knowledge rather than occupation-specific skills or classical subject-focused study. Despite being viewed by some as 'intellectually adrift' (Lucas, 2004, p.7) due to the distinction from established forms of knowledge, technical education offered a potential middle ground for mathematics between embedded occupation-specific skills and a liberal approach to the subject. In the terms used by Ernest (2004), this represented a wider utilitarian view of mathematics, rather than a restriction to practical work-related knowledge, but was still distinct from the academic approach that incorporated an appreciation of the discipline with advanced specialist knowledge.

During the twentieth century, vocational and academic education remained largely disconnected, despite local authorities gaining responsibility for both strands from the 1944 Education Act onwards (Fieldhouse, 1996). Different forms of knowledge were reinforced through distinctive but separate curricula and qualifications for academic and vocational learning. Mathematics in vocational education was focussed on work-related skills that were embedded into vocational competencies. In academic pathways abstract mathematics became highly valued and necessary for progression. These contrasting purposes for mathematics reflected a 'stratification of 
knowledge' (Young, 1998, p.51) that privileged academic 'learning' over vocational 'training'(Hyland, 1999) and reflected hierarchical societal structures.

The 'middle ground' remained a relatively unexplored area of the mathematics curriculum until the latter part of the twentieth century when high youth unemployment prompted significant growth in vocational education for young people. Hyland and Merrill (2003) describe how various youth-training schemes in the 1970s and 1980s led to a greater recognition of the value of mathematics as a general preparation for employment. A call for employment-readiness, accompanied by concerns about skills gaps in subjects such as mathematics, continues to be echoed by the likes of the Confederation of British Industry (Confederation of British Industry, 2015).

The landmark Cockcroft Report of 1982 emphasised the importance of numeracy skills for everyday life and work. Meanwhile, in vocational education there was considerable interest in identifying generic skills that would be useful for a wide range of occupations (Hyland, 1999). Although lists of skills were developed by different bodies in an attempt to define 'core' skills, they did not always include mathematics. With the mandatory inclusion of 'application of number' in new General National Vocational Qualifications (GNVQ) and National Vocational Qualifications ${ }^{\mathrm{ii}}$ (NVQ) in the 1990s, mathematics became an essential component of vocational training (Hyland, 1999). The aim of introducing 'core skills' was to help students develop generic employment skills but, in practice, the curriculum was best suited to a narrow embedded approach focused on occupation-specific applications. Despite trying to introduce these core skills into both academic and vocational post-16 learning, they were soon rejected from academic pathways. Conceptually, core skills was problematic due to the assumed generalizability and transferability of these skills between contexts (Green, 1998). Hyland and Johnson (1998) considered such free-standing generic skill 
qualifications as untenable, a position also adopted later by Wolf (2011) regarding subsequent qualifications. Despite multiple criticisms of core skills (Green, 1998), these developments laid the foundations for a possible bridging of the academic-vocational divide .

The Dearing Report (1996) supported the development of these generic skills but redefined them as 'key skills'. New qualifications appeared and the inclusion of Application of Number as a Key Skills qualification was recommended for students on both academic and vocational pathways (QCA, 2000). This approach to developing students' generic mathematical skills suggested a shift towards a common ground where both mathematical knowledge and applications were valued. The assessment included both an application component and a formal test. Approaches that linked the mathematics to the vocational programme and emphasized a vocational purpose for the skills became popular in colleges (Eldred, 2005; Roberts et al., 2005). These 'generic' skills therefore became more embedded and contextualised into vocational training, although the test component was disconnected from vocational practices.

On the heels of the Dearing recommendations, Moser (1999) highlighted low levels of numeracy in the adult population, which resulted in an expansion of adult numeracy provision in England. A new core curriculum for adult numeracy (DfES, 2001) underpinned the Key Skills Application of Number specifications and was linked to the National Curriculum in schools. It might have appeared that some consistency had been achieved across the academic, vocational and adult strands of education but the assessments showed some significant differences in the underlying educational purposes. The Adult Numeracy national test focused on assessing knowledge of basic mathematical processes whereas the Key Skills assessment included an identical test but 
also a portfolio of contextualised work to demonstrate competency with application skills in familiar contexts.

The inadequacies of the mathematics curriculum and qualifications, for both academic and vocational purposes, were brought into focus by the Smith Report (2004) which argued that neither the needs of higher education nor those of employers were being met. The report identified a need to develop new pathways for mathematics in the 14-19 phase and, alongside the recommendations made by Tomlinson (2004), provided the impetus for significant change.

A renewed call for students to develop mathematical skills for everyday life and employment (DfES, 2005) led to the replacement of Key Skills by new Functional Skills qualifications. The Functional Mathematics curriculum centred on applications and problem-solving in 'realistic' life situations (QCA, 2007). Moving away from specific applications in familiar contexts towards developing transferable problemsolving skills, the approach was designed to meet the demands of the workplace where tasks are non-routine (Hoyles, Wolf, Molyneux-Hodgson, \& Kent, 2002) and complex situations require interpretation (Hodgen \& Marks, 2013). Whether this curriculum could fulfil its comprehensive purpose and succeed where core and Key Skills had failed was, however, debatable (Hodgson \& Spours, 2008; Wake, 2005). In practice, Functional Mathematics in schools became embedded into GCSE Mathematics and quickly disappeared, but in Further Education it was retained and used extensively with adult and vocational students. The research reported herein investigates the experiences of vocational students, aged 16-18 years, learning Functional Mathematics.

\section{Research design}

Although classroom research is undertaken at a particular point in time and space, it is 
necessarily also research of the imbricated layers of historical policy and educational practices described above (Noyes, 2013). The main research study on which this paper is based sought to understand the effects of this amalgam of national and college-level policies, organisational structures, commonly accepted pedagogic practices and classroom cultures on students learning mathematics in Further Education. In view of the limited research attention paid to mathematics education in FE the study was exploratory as well as explanatory and was not strongly framed by a particular theoretical stance. In this paper three particular questions are explored:

(1) How do vocational students view the place and purpose of mathematics?

(2) What features of college policy and practice influence their perspectives?

(3) What impact does this have on their learning experience?

A nested case study methodology, employing a multi-method approach was used to generate rich data and allow for triangulation between respondents, methods and sites. Three large FE colleges in the Midlands of England with different organisational approaches to Functional Mathematics formed the primary cases. Preliminary discussions with colleges suggested that their organisational approaches could be appropriately described using the terms centralised and dispersed to indicate the locations of Functional Mathematics teachers within contrasting college staffing structures and the associated management focus. College A had a strong centralised Functional Mathematics team who worked across many of the college departments, although some vocational areas had appointed their own Functional Mathematics teachers who were situated in the department as part of the vocational team. College B had a fully dispersed structure in which Functional Mathematics teachers were situated 
within vocational departments, whilst College $\mathrm{C}$ had recently moved to a dispersed arrangement but still retained a small centralised team.

Each college offered a wide range of courses and this made comparisons possible between colleges in the same vocational areas. Student participants were mainly on Level 2 vocational programmes and were working at a similar level of Functional Mathematics (Level 1 or $2^{\mathrm{iii}}$ ). A total of seventeen student groups were recruited from the Construction, Hair and Beauty and Public Services ${ }^{\text {iv }}$ areas. Each student group, together with their Functional Mathematics teacher, formed a case study nested within the college. Data were generated over a nine-month period from focus groups, card-sorting activities and from questionnaires and interviews with Functional Mathematics and vocational teachers. In addition, observations of several Functional Mathematics lessons and one vocational lesson were conducted for each of the student groups.

The student focus groups each met three times during the academic year to discuss their transition from school to college, experiences of Functional Mathematics and opinions about a range of exemplar mathematics curriculum materials. The first and third term discussions were preceded by individual card-sorting activities in which students indicated how strongly they agreed or disagreed with statements about learning mathematics in school and in college. These responses were coded, summarised and treated as ordinal data in the analysis. The analysis of the qualitative data was conducted using a constant comparison method to identify emerging themes, which were then explored further using cross-case and within-case comparisons.

\section{Research findings}

The present paper investigates the location of mathematics within the learning 
experiences of vocational students, by considering their views of its place and purpose alongside the different policies and practices adopted by colleges. This section begins with a brief description of the changing perspectives towards mathematics and attitudinal shifts experienced by some students in their transition from school to FE college (see Dalby (2014) for more information). Four brief case portraits of Functional Mathematics groups (and their teachers) are then presented to highlight key features of college policy and practice that had an impact on the student experience. They are analytic 'sketches', rather than comprehensive accounts, but the main features are a fair reflection of the full data and illustrate the main themes that emerged from the study. In the following section the key themes are summarised and we consider how the positioning of mathematics within students' experiences through college policies and practices is related to the concepts of integration or isolation.

Analysis of the first set of individual card-sorting activities showed that many of the students in this study were disaffected by their experience of mathematics in school, which was not unexpected (see Nardi and Steward, 2003). There were, however, some significant shifts towards more positive attitudes in college and the focus group discussions supported this analysis. The results shown in Table 1 indicate that many students considered Functional Mathematics lessons in college to be less stressful, less difficult, less confusing and more interesting than GCSE Mathematics in school. These students reported having more positive relationships with their teachers, better subject understanding and increased confidence.

Table 1: Differences in individual students' ratings of statements about their experience of mathematics in school and college (Term 1)

\begin{tabular}{|c|c|c|c|c|c|c|c|c|c|c|c|c|c|c|c|}
\hline \multirow{2}{*}{ Statement } & \multicolumn{11}{|c|}{ Difference in student rating $($ score $=$ college - school) } & \multirow{2}{*}{ Negative } & \multirow{2}{*}{\begin{tabular}{|c|} 
No \\
change
\end{tabular}} & \multirow[t]{2}{*}{ Positive } & \multirow[t]{2}{*}{$\mathrm{Z}$ value } \\
\hline & -5 & -4 & -3 & -2 & -1 & 0 & 1 & 2 & 3 & 4 & 5 & & & & \\
\hline
\end{tabular}




\begin{tabular}{|c|c|c|c|c|c|c|c|c|c|c|c|c|c|c|c|}
\hline I worked hard & 0 & 1 & 2 & 4 & 18 & 36 & 28 & 10 & 2 & 1 & 0 & 25 & 36 & 41 & -1.846 \\
\hline It was difficult & 0 & 0 & 4 & 22 & 29 & 28 & 16 & 3 & 1 & 0 & 0 & 55 & 28 & 20 & $-3.926^{* *}$ \\
\hline I got distracted & 0 & 1 & 8 & 20 & 25 & 29 & 12 & 6 & 1 & 1 & 0 & 54 & 29 & 20 & $-3.836^{* *}$ \\
\hline I liked maths & 1 & 1 & 2 & 4 & 15 & 39 & 22 & 12 & 5 & 2 & 0 & 23 & 39 & 41 & $-2.125^{*}$ \\
\hline I felt stressed & 0 & 2 & 9 & 16 & 28 & 33 & 9 & 4 & 1 & 1 & 0 & 55 & 33 & 15 & $-4.661 * *$ \\
\hline I was bored & 0 & 4 & 8 & 20 & 18 & 26 & 17 & 7 & 1 & 2 & 0 & 50 & 26 & 27 & $-2.507^{*}$ \\
\hline I liked the teacher & 0 & 1 & 3 & 4 & 9 & 22 & 16 & 18 & 18 & 12 & 0 & 17 & 22 & 64 & $-5.111^{* *}$ \\
\hline I felt confident & 1 & 0 & 1 & 2 & 9 & 47 & 21 & 15 & 7 & 0 & 0 & 13 & 47 & 43 & $-3.875 * *$ \\
\hline It was interesting & 1 & 0 & 0 & 4 & 12 & 33 & 27 & 22 & 3 & 1 & 0 & 17 & 33 & 53 & $-4.183 * *$ \\
\hline I understood it & 0 & 0 & 2 & 1 & 11 & 37 & 33 & 14 & 5 & 0 & 0 & 14 & 37 & 52 & $-4.554 * *$ \\
\hline It was confusing & 0 & 1 & 5 & 12 & 24 & 41 & 13 & 5 & 1 & 0 & 1 & 42 & 41 & 20 & $-2.667 * *$ \\
\hline I could have done better & 0 & 2 & 6 & 17 & 26 & 28 & 16 & 6 & 1 & 1 & 0 & 51 & 28 & 24 & $-3.002^{* *}$ \\
\hline
\end{tabular}

Note: * Significant at $5 \%$ level; ** Significant at $1 \%$ level.

The reasons for any attitudinal changes were explored in the focus groups. Although reactions were sometimes mixed, student attitudes within groups were generally consistent though not always positive. This bifurcation into more positively and negatively disposed groups is explored by studying contrasting cases of Functional Mathematics classes. Each of the following case portraits has been selected to illustrate several key features and allow for comparison of contrasting aspects of policy and practice. These case portraits present key extracts of relevance from the case studies, and are based on an analysis of triangulated data from lesson observations, teacher interviews, teacher questionnaires and student focus groups.

\section{Case 1: Elliott's Construction group}

Elliott is a full-time Functional Mathematics teacher in a dispersed staffing structure, teaching solely within the Construction department. He is managed as part of the vocational team and his teaching is timetabled in classrooms allocated to the department. Sharing a staff room with the Construction teachers means he works closely with vocational staff when designing tasks for his Functional Mathematics lessons to ensure they represent authentic uses of mathematics with accurate contextual details. 
Elliot frequently refers to applications of mathematics from the construction industry in his lessons, linking his teaching to vocational schemes of work. He sets problems in contexts relating to building trades and incorporates relevant practical activities. For example, students construct accurate models of houses to use with a scale drawing of a new estate so that they can carry out a series of practical problem-solving tasks, such as designing plans for the supply of the basic amenities and calculating the costs. In another lesson students use authentic floor plans and images of houses to draw elevations. These types of task connect mathematics to vocational learning in an integrated approach. Students recognise the vocationally-related purpose for learning mathematics and contrast this with their school experience:

Because at school you was just doing maths to get grades where you'd do certain types of maths just to get you better grades but here you do maths that's going to help you with future life and stuff that you're always going to need (Connor)

Connor contrasts GCSE mathematics, which he perceives as being about gaining a qualification, with Functional Mathematics, which he believes is helping him to develop useful skills for his future. Most of this group describe their previous experience of mathematics in terms of disaffection and low-attainment but they talk positively about the relevance of the tasks used by Elliott and the connections to their vocational curriculum. For them, Functional Mathematics now has a purpose beyond being an academic subject. They are finding that mathematics can be relevant to their vocational training and this in turn results in more positive attitudes and better engagement with lessons.

\section{Case 2: Rachel's Construction group}

Rachel is a Functional Mathematics teacher in a dispersed structure, based in the 
Construction department and teaching in rooms within the department. She has daily interactions with the vocational teachers. Her approach to teaching Functional Mathematics is, in contrast to Elliott, to avoid familiar vocational applications in favour of a diversity of contexts for problem-solving. Rachel's approach to developing general problem-solving skills involves various puzzles and tasks that require the development and implementation of systems or strategies. The contexts for these problems are often fictitious or use scenarios with no connection to the vocational area. The students in this group have difficulty seeing the relevance of Functional Mathematics, as one student explains: 'There was nothing new in it that we did that I can't remember doing at school.' (Ethan).

These students make comparisons to GCSE Mathematics in terms of curriculum content and do not consider themselves to have developed any additional skills in using and applying mathematics. From their perspective, Functional Mathematics is similar to GCSE but less challenging. It is, therefore, just another qualification with no particular relevance to their vocational course or their personal development, other than being a college-imposed requirement for progression to the next level of training.

Many of this group do not see the need to study Functional Mathematics as they already have a grade $\mathrm{C}$ at GCSE. The policy of the college, however, requires them to take one Functional Skill qualification and the department stipulates mathematics. Through teaching approaches that fail to integrate or connect Functional Mathematics with students' vocational learning the subject is perceived as irrelevant. Students continue to associate mathematics with gaining a qualification rather than learning useful skills. 


\section{Case 3: Richard's Hairdressing group}

Richard is a Functional Mathematics teacher within a dispersed structure, situated in the Hair and Beauty department and teaching classes from this vocational area but in various rooms across the college. His lessons are organised around a series of tasks or projects that are directly related to the vocational course, such as refurbishing a hairdressing salon, drawing up a business plan for a new salon or planning an appointments schedule. These tasks use relevant, authentic information and so are strongly linked to the students' vocational programme. Richard also uses scenarios that arise during informal conversations with students to pose impromptu problems or illustrate how mathematics is useful in their personal lives or intended careers.

He's doing it in a scenario so that makes it more interesting and more fun to learn about rather than just being sat down writing on the board and working out. (Leanne)

The use of 'real life' scenarios has stimulated Leanne's interest in learning mathematics. She also describes in the focus group how she has come to understand its relevance to hairdressing. Discovering a practical purpose for mathematics in relation to her vocational learning has helped her to re-engage with mathematics and she later achieves success in the Functional Mathematics examination. Ellie, from the same group, explains a similar impact on her achievement:

I've learned more than I did in school and I was in school for, what, four years? I think I've learned more in the past two years in maths than I have in the past four years in school. (Ellie)

Although the opinions within this group are not unanimous, there is agreement that Functional Mathematics involves learning relevant skills. These students do not already 
have GCSE Mathematics at grade C and generally lack confidence. Many approached the prospect of a Functional Mathematics course with reluctance and did not initially understand the relevance of mathematics to their vocational learning. The connections to hairdressing convinced most of the group, however, of their need to use mathematics and resulted in an intrinsic purpose for learning.

\section{Case 4: Kathy's Hairdressing group}

Kathy is a mathematics specialist within a centralised team of Functional Skills teachers. She teaches groups from several vocational departments. This group of hairdressing students has lessons in a dedicated Functional Skills room some distance from the hairdressing vocational base. Kathy's teaching is based on a workshop approach, in which students work individually, at their own pace, using printed booklets on different mathematical topics. These include questions in a range of contexts but with little connection to the vocational area.

In the focus group the students discussed initially how they valued the flexibility and personal independence of the workshop approach but, as the year progressed, they expressed their boredom with the repetitive use of the booklet system. Once the attractiveness of this new teaching method diminished, they began to question the purpose of learning the subject. Amber explained that 'If I had the choice then I wouldn't go; I'm not going to use it in everyday life' and this reflected the general attitude of the group. For them, Functional Mathematics lacked a practical use and their motivation declined accordingly, despite the qualification being a requirement for completion of their vocational course. These students see little connection between mathematics and hairdressing, although they do acknowledge that some mathematics is 
needed for their intended occupation and that there is room for improvement in their skills.

This disconnected perception of Functional Mathematics was clear in discussions about the use of contextualised questions, as Naomi explained: 'Because if it was about hairdressing then I'd be thinking "No, you do it like this" instead'. The connection between a mathematics problem in a hairdressing context and typical workplace practices in a salon appear tenuous. The use of context in these lessons is often superficial and unrealistic. Rather than connecting Functional Mathematics with hairdressing this suggests that mathematics is irrelevant to, or isolated from, students' work experiences. The purpose of learning mathematics for these students is more closely related to passing an examination than it is to supporting their vocational learning.

\section{Key themes}

A comparative cross-case analysis of the full set of case studies identified a number of key themes and features within the case study groups that are relevant to the research questions. These features are summarised in this section with reference to the strong twin themes of isolation or integration which provide some common threads through a complex interaction of college policy and practice with students' perceptions of mathematics.

For all of these groups, Functional Mathematics is taught in discrete sessions and therefore the starting point is one of isolation rather than integration or connection between mathematics and vocational learning. Furthermore, students' experiences of GCSE Mathematics in school have generally been of disaffection and they approach 
Functional Mathematics with views of the subject as an academic discipline with little relevance or connection to their vocational learning.

Table 2 summarises the key features that shaped student perceptions of the isolation or integration of mathematics within their learning experience in college. The cases exemplify the general patterns found through the full dataset.

Table 2: Summary of key characteristics of the four case study classrooms.

\begin{tabular}{|l|c|c|c|c|c|c|c|}
\hline Teacher & College & $\begin{array}{c}\text { Vocational } \\
\text { area }\end{array}$ & $\begin{array}{c}\text { Staffing } \\
\text { structure }\end{array}$ & $\begin{array}{c}\text { Use of } \\
\text { tasks in } \\
\text { vocational } \\
\text { context }\end{array}$ & $\begin{array}{c}\text { Classroom } \\
\text { within } \\
\text { vocational } \\
\text { area }\end{array}$ & $\begin{array}{c}\text { Links } \\
\text { between } \\
\text { mathematics } \\
\text { lessons and } \\
\text { vocational } \\
\text { programme }\end{array}$ & $\begin{array}{c}\text { Student } \\
\text { views of the } \\
\text { relevance of } \\
\text { mathematics }\end{array}$ \\
\hline Elliott & C & Construction & Dispersed & $\checkmark$ & $\checkmark$ & $\checkmark$ & Positive \\
\hline Rachel & B & Construction & Dispersed & $\times$ & $\checkmark$ & $\times$ & Negative \\
\hline Richard & A & Hairdressing & Dispersed & $\checkmark$ & $\times$ & $\checkmark$ & Positive \\
\hline Kathy & C & Hairdressing & Centralised & $\times$ & $\times$ & $\times$ & Negative \\
\hline
\end{tabular}

Elliott and Rachel may teach in the same vocational area and are both located within the vocational department, in dispersed structures, but their students' views of the relevance of mathematics differ considerably. Elliott's use of vocational contexts and connections to the vocational course contribute to his students' views of Functional Mathematics as relevant and useful. Rachel has similar opportunities to make meaningful connections as a teacher situated within the Construction department but chooses an alternative approach to teaching Functional Mathematics that generalises, abstracts and thereby isolates mathematics from vocational learning.

A comparison of Richard's and Kathy's groups, both in the Hairdressing area but in different colleges, shows how using contextualised tasks and making curriculum connections can support students to understand the relevance of mathematics. Kathy is 
part of a centralised Functional Mathematics team and teaches groups from several vocational areas. Given her isolation from the vocational area, a generic approach to teaching is understandable. Lacking opportunities to plan with vocational teachers, her teaching is disconnected from students' vocational learning and thereby relatively less engaging.

The policy of situating Functional Mathematics teachers within vocational teams presents opportunities to connect mathematical and vocational learning in an integrated approach. Elliott and Richard make use of this potential, making effective connections through the use of mathematical tasks in authentic vocational contexts. They also use informal discussions to enhance connections or explain other applications to student lives. Students thereby understand the purpose of mathematics in relation to their current interests and values. Although this may be seen as a somewhat utilitarian view of mathematics (Ernest, 2004), their students are engaged, which is a significant improvement upon their previous experiences and attitudes.

Connecting mathematics to students' lives and values also contributes to a classroom culture that more closely resembles that of the typical vocational learning environment. In lesson observations, differences between vocational and Functional Mathematics sessions in relation to physical space, student responsibilities, time scales for tasks, peer learning opportunities and teacher roles betray a cultural division that only a few teachers in the study attempted to bridge. The more integrated approach to the curriculum adopted by teachers such as Elliott and Richard mirrors values that are important in the vocational area. This contributes to a classroom culture that is more closely connected to the vocational and is therefore valued by students.

The second policy that had a strong, and sometimes detrimental, influence on the student experience was concerned with which students should take a Functional 
Mathematics course. In Rachel's group, students who had already achieved GCSE mathematics at grade $\mathrm{C}$ or above were required to take Functional Mathematics but became resentful because they could see no added value in gaining a Functional Mathematics qualification at an equivalent level. In contrast, low-attaining students in Richard and Elliott's groups were initially reluctant to engage with Functional Mathematics but their on-course experience resulted in changed attitudes as they began to discover a vocationally-related purpose for the subject. For these students discovering a use-value for mathematics was an important factor in their re-engagement.

Student focus groups highlighted how the timetabling and rooming of Functional Mathematics sometimes reinforced perceptions that the subject was an isolated, disconnected addition to their vocational programme. Disjointed arrangements, such as using rooms at a distance from the students' vocational base area, or timetabling Functional Mathematics on a separate day from the vocational programme, generated negative attitudes and gave the impression that the subject was not an integrated part of their study programme.

The data show how connections between mathematics lessons and the vocational area are both a) variable in practice and b) important influencers of students' views of the relevance and value of mathematics for their lives. Differences in the systems, curriculum and classroom cultures between mathematics and vocational education were sometimes bridged through the building of meaningful connections and facilitated by structures that integrated mathematics teachers into vocational departments. Although Functional Mathematics lessons were timetabled separately and were sometimes physically distant from the vocational area, making connections at other levels brought the two learning experiences closer together and had a positive impact on student attitudes, engagement and understanding. 
The findings discussed above show that the historical division between academic and vocational education (Pring et al 2003) is still visible in Further Education colleges in the enactment of mathematics policy and practice. Differences are manifested in various ways and these affect vocational students' views of mathematics. Nevertheless, the case studies also demonstrate the positive impact of concerted efforts to provide a more integrated learning experience, both in terms of colleges' organisational policies and through teachers' approaches to curriculum and pedagogy. Table 3 summarises the key features that contribute to students' perceptions of mathematics learning as isolated from, or integrated with, vocational learning.

Table 3: Integration and isolation at different levels within the student experience.

\begin{tabular}{|l|l|l|}
\hline \multicolumn{1}{|c|}{ Level } & \multicolumn{1}{|c|}{ Integrated } & \multicolumn{1}{|c|}{ Isolated } \\
\hline $\begin{array}{l}\text { College staffing } \\
\text { structures }\end{array}$ & $\begin{array}{l}\text { Mathematics teachers are } \\
\text { dispersed into vocational } \\
\text { areas and placed into } \\
\text { vocational teams. }\end{array}$ & $\begin{array}{l}\text { Mathematics teachers are part of } \\
\text { a centralised team and } \\
\text { unconnected to vocational staff. }\end{array}$ \\
\hline Programme organisation & $\begin{array}{l}\text { Mathematics sessions are } \\
\text { integrated into the vocational } \\
\text { timetable and taught in rooms } \\
\text { within the vocational area of } \\
\text { the college. }\end{array}$ & $\begin{array}{l}\text { Mathematics sessions are } \\
\text { timetabled on a separate day } \\
\text { from the vocational sessions } \\
\text { and/or in a classroom located at } \\
\text { a distance from the vocational } \\
\text { area. }\end{array}$ \\
\hline $\begin{array}{l}\text { Curriculum and } \\
\text { qualifications }\end{array}$ & $\begin{array}{l}\text { Functional Mathematics } \\
\text { involves applications of } \\
\text { mathematics in 'real life' } \\
\text { contexts. This enables } \\
\text { connections to be constructed } \\
\text { to vocational experience. }\end{array}$ & $\begin{array}{l}\text { GCSE mathematics is a } \\
\text { knowledge-based academic } \\
\text { subject. The content appears } \\
\text { unrelated to students' vocational } \\
\text { experience. }\end{array}$ \\
\hline Pedagogy & $\begin{array}{l}\text { Realistic contexts from the } \\
\text { vocational area are used to } \\
\text { relate mathematics to } \\
\text { students' vocational } \\
\text { programme and interests. } \\
\text { Classroom cultures reflect } \\
\text { vocational values. } \\
\text { Mathematics topics are }\end{array}$ & $\begin{array}{l}\text { Mathematics is taught using } \\
\text { generic approaches. Contexts are } \\
\text { unrealistic and/or unrelated to } \\
\text { students' vocational } \\
\text { programmes. Classroom cultures } \\
\text { resemble those in a traditional } \\
\text { school mathematics lessons. }\end{array}$ \\
\hline
\end{tabular}




\begin{tabular}{|l|l|l|}
\hline & $\begin{array}{l}\text { synchronised with vocational } \\
\text { schemes of work. }\end{array}$ & \\
\hline $\begin{array}{l}\text { Student perceptions of } \\
\text { mathematics }\end{array}$ & $\begin{array}{l}\text { Mathematics is seen as a } \\
\text { useful tool and an essential } \\
\text { part of vocational learning. }\end{array}$ & $\begin{array}{l}\text { Mathematics is seen as a remote } \\
\text { and irrelevant additional subject } \\
\text { with no purpose. }\end{array}$ \\
\hline
\end{tabular}

\section{Implications}

\section{Intersecting levels of influence}

College policies for staffing and programme organisation impact upon student perceptions of mathematics as an isolated or integrated subject. Government policy affects the type of curriculum offered to students, whilst colleges and teachers have respective agency through internal policies, programme planning and classroom practices. At each level - college, programme and classroom - an integrated approach seems to contribute towards more positive views of mathematics and the research suggests that this results in improved attitudes and engagement.

The best-case scenario for an integrated approach would be one in which each level of the system is oriented towards integration. When a teacher's Functional Mathematics pedagogy connects mathematics to the vocational learning, where there is close collaboration with vocational staff and teaching takes place in close proximity to the vocational base there is greater synergy between the college, programme, curriculum and pedagogic levels. This desirable scenario is not always present but some of the levels in Table 3 are more critical than others. For example, evidence from other cases within the study suggests that a strongly integrated pedagogy can help to overcome the impact of Functional Mathematics teaching being centralised. In contrast, a Functional Mathematics teacher who is placed within a vocational department might still adopt a disconnected or isolated pedagogy. In both of these cases, activity at one 
level tends to counteract that at another. This inter-linking reinforces the idea that understanding mathematics education in FE needs to be considered as a complex, multiscale problem.

College structures with Functional Mathematics dispersed amongst vocational departments provide, on the basis of evidence from this study, better opportunities to integrate mathematics and vocational learning but positioning a Functional Mathematics teacher into a vocational team is not sufficient to ensure closer connections. Better integration of curriculum and pedagogy are also necessary to develop a stronger sense of the use-value and relevance of mathematics to vocational learning. There is evidence that organisational arrangements, such as the timetabling of Functional Mathematics, can contribute to students' perceptions of the isolation of the subject but these can be countered by effective pedagogy and an appropriate curriculum.

\section{Curricular and pedagogic relevance}

Curriculum and pedagogy are, unsurprisingly, identified from this study as strong influences that are closely linked to the effectiveness of mathematics teaching and learning. Providing a relevant curriculum and developing classroom practices that communicate an integrated view of mathematics is, however, not easy given the direction of current government policy.

With respect to the curriculum, some integration was achieved in Functional Mathematics lessons by constructing meaningful connections to students' lives through the use of contextualised problems and 'realistic' scenarios (QCA, 2007). Although the Functional Mathematics curriculum is not directly focussed on application in familiar contexts, as it was with Key Skills (QCA, 2000), some teachers emphasised a practical purpose for mathematics in relation to students' vocational interests and values. In this 
way the Functional Mathematics curriculum, although theoretically positioned in the 'middle ground' as a means of developing a generic set of skills, is experienced by some students as having close connections to their vocational training. These learning experiences highlight the relevance and use-value of mathematics, leading to better engagement and reported improvements in understanding.

In contrast, many of the students saw little relevance for the GCSE Mathematics they had learned in school. Although they acknowledged its exchange-value they perceived it to be an academic subject and therefore isolated from their current learning experience. These students valued vocational learning over academic study, in contrast to normative knowledge hierarchies (Young, 1998). For vocational students to reengage with mathematics the curriculum needs to relate to vocational values rather than defaulting to academic expectations. Recognising the personal use-value of mathematics was fundamental to the process of replacing students' previous views of mathematics with ones that were more aligned to their vocational aspirations.

The linking of mathematics and vocational classroom cultures through the alignment of values is also important in developing an integrated approach. Features of the general organisational culture in FE colleges, such as more equitable social structures, informal learning environments and teacher-student relationships, help to generate positive attitudes when enacted in mathematics classrooms. Classes with these characteristics align well with students' vocational experiences and values. This harmonization of values and practices enables traditional divisions between mathematics and vocational classrooms to be bridged. With a more coherent cultural environment across student timetables and less distinction between mathematics and vocational classroom cultures, mathematics is more readily viewed as an integral part of a student programme as opposed to an unwelcome appendage. 


\section{Maintaining the 'middle ground'}

The clear separation between an academic and a vocational curriculum makes it difficult to see mathematics as a vocationally-relevant subject for students without taking a very narrow approach and teaching only occupation-specific skills. The deeply ingrained historical divisions in education systems and structures, curriculum and cultures demands a multi-level approach to bridge such divisions and avoid the tendency to bifurcate academic and vocational purposes for mathematics in FE. This research shows how integrated approaches to Functional Mathematics offer a transformative learning experience for students that helps to locate mathematics in the 'middle ground' between an isolated GCSE and highly embedded forms such as core and Key Skills (Eldred, 2005; Roberts et al., 2005). The value and status of the Functional Mathematics qualification is, however, contested in current policy debates. It is considered inferior to GCSE Mathematics and this might well undermine the positive impact that Functional Mathematics has had for many learners.

The association of Functional Mathematics with vocational education and its disappearance from GCSE Mathematics in recent years reinforces the stratification of mathematics knowledge from the $19^{\text {th }}$ Century discussed earlier. Any qualification designed for the needs of vocational learners rather than simply for academic progression can easily become perceived as inferior. This is an endemic problem that is indicative of the challenges facing the development of a modern vocational educational system in England. Creating a mathematics curriculum and appropriate pedagogy that can meet both purposes remains elusive in such a divided system (Hayward \& Fernandez, 2004). 


\section{Conclusions}

Throughout this paper, questions about the purpose of learning mathematics are never far from the surface. The multiple purposes for mathematics in policymaking, for example as skills for life and work (Cockcroft, 1982; DfES, 2005) versus the acquisition of minimum level of mathematical knowledge (Wolf 2011), generates contradictions for vocational students and FE teachers and managers. Studies of mathematics in the workplace suggest that most occupations only require basic mathematical knowledge but the ability to interpret situations and apply appropriate mathematics is also vital (Hodgen \& Marks, 2013; Hoyles et al., 2002). If the purpose of teaching mathematics to vocational students is preparation for work, then integrated Functional Mathematics is arguably more beneficial than the GCSE qualification since it provides opportunities to develop skills in practical problem-solving and application of mathematics using vocationally-relevant scenarios. In contrast, GCSE specifications and assessments privilege abstract, isolated knowledge acquisition.

Alternatively, if the aim is to ensure all students reach an accepted minimum standard in mathematics then the findings from this study indicate that setting this standard as a GCSE mathematics grade C may reinforce prior disaffection and disinterest amongst post-16 vocational students. Whilst aiming to raise standards, such a policy further disadvantages and demotivates low-attaining learners. Furthermore, the prioritisation of GCSE mathematics seems to reinforce the long-standing inequity between academic and vocational knowledge by placing greater value on an academic qualification than on the skills required for vocational employment, even for those who have chosen a vocational pathway. 
A curriculum with relevance and purpose for vocational students may appear less academically challenging but this research provides evidence of some significant positive effects on student attitudes and engagement when integrated approaches to teaching are adopted. In a system that continues to place lower value on vocationallyrelated courses, acquiring worthwhile mathematical skills for employment is at risk of taking second place to maintaining disengaged learners in cycles of failure as they strive for 'success' in GCSE Mathematics.

\section{Notes}

\footnotetext{
${ }^{\mathrm{i}}$ There are fundamental differences in the curriculum between GCSE Mathematics, which is a knowledge-based qualification, compared to Functional Mathematics which has a narrower range of content but a greater emphasis on 'real life' applications and problem-solving.

ii National Vocational Qualifications were introduced to assess the competencies required for specific occupations. General National Vocational Qualifications involved a wider range of knowledge, skills and competencies that were considered to underpin a range of occupations with a vocational area.

${ }^{\text {iii }}$ Level 2 corresponds broadly to the level of a GCSE grade C or above. Level 1 corresponds broadly to the level of lower GCSE grades (D-G).

${ }^{\text {iv }}$ Public Services programmes in England focus on preparation for entry to the Armed Services or Emergency Services.
} 


\section{References}

City \& Guilds. (2012). Ways into Work: Views of Young People. London: City and Guilds.

Cockcroft, W. H. (1982). Mathematics Counts: Report of the Committee of Inquiry into the Teaching of Mathematics in Schools. London: Her Majesty's Stationery Office.

Confederation of British Industry. (2015). Inspiring growth: CBI/Pearson education and skills survey 2015. Confederation of British Industry/Pearson. London: Confederation of British Industry/Pearson.

Crawford, C., \& Cribb, J. (2013). Reading and maths skills at age 10 and earnings in later life: a brief analysis using the British Cohort Study. Centre for Analysis of Youth Transitions Report(3).

Dalby, D. (2014). A study of the experiences of vocational students learning functional mathematics in Further Education colleges. Unpublished thesis. University of Nottingham.

Dearing, R. (1996). Review of qualifications for 16-19 year olds. London: School Curriculum and Assessment Authority.

DfE. (2014). GCSE and equivalent results in England 2012-2013 revised. https://http://www.gov.uk/government/publications/gcse-and-equivalent-resultsin-england-2012-to-2013-revised

DfES. (2001). Adult Numeracy Core Curriculum. London: Department for Education and Skills.

DfES. (2005). 14-19 Education and Skills. London: HMSO.

Education and Training Foundation. (2014). Effective Practices in Post-16 Vocational Maths. London: The Research Base.

Eldred, J. (2005). Developing embedded literacy, language and numeracy: supporting achievement. Leicester: NIACE.

Ernest, P. (2004). Relevance versus Utility. In B. Clarke, D. M. Clarke, G. Emanuaelson, B. Johansson, D. Lambin, F. Lester, A. Wallby \& K. Wallby (Eds.), International Perspectives on Learning and Teaching Mathematics (pp. 313-327). Goteborg: National Center for Mathematics Education

Fieldhouse, R. (1996). A History of Modern British Adult Education. Leicester: NIACE. 
Green, A. (1998). Core skills, key skills and general culture: in search of the common foundation in vocational education. Evaluation \& Research in Education, 12(1), 23-43.

Hayward, G., \& Fernandez, R. M. (2004). From core skills to key skills: fast forward or back to the future? Oxford Review of Education, 30(1), 117-145.

Hodgen, J., \& Marks, R. (2013). The Employment Equation: Why our young people need more maths for today's jobs. A report for the Sutton Trust. Retrieved from http://www.suttontrust.com/public/documents/mathsreport-final.pdf

Hodgson, A., \& Spours, K. (2008). Education and training 14-19: curriculum, qualifications and organization. London: Sage.

Hoyles, C., Wolf, A., Molyneux-Hodgson, S., \& Kent, P. (2002). Mathematical skills in the workplace: final report to the Science Technology and Mathematics Council. London: Institute of Education and the STM Council.

Hyland, T. (1999). Vocational studies, lifelong learning and social values: investigating education, training and NVQs under the new deal. Aldershot: Ashgate.

Hyland, T., \& Johnson, S. (1998). Of cabbages and key skills: Exploding the mythology of core transferable skills in post-school education. Journal of Further and Higher Education, 22(2), 163-172.

Hyland, T., \& Merrill, B. (2003). The changing face of Further Education: lifelong learning, inclusion and community values in further education. Abingdon: Routledge.

Lucas, N. (2004). Teaching in further education: New perspectives for a changing context. London: Institute of Education.

Moser, C. (1999). Improving Literacy and Numeracy: A Fresh Start. London: Department for Education and Employment.

Nardi, E., \& Steward, S. (2003). Is mathematics TIRED? A profile of quiet disaffection in the secondary mathematics classroom. British Educational Research Journal, 29(3), 345-366.

Noyes, A. (2013). Scale in education research: towards a multi-scale methodology. International Journal of Research \& Method in Education, 36(2), 101-116.

Parsons, S., \& Bynner, J. (2005). Does Numeracy Matter More? London: National Research and Development Centre for Adult Literacy and Numeracy.

Pring, R., Hayward, G., Hodgson, A., Johnson, J., Keep, E., Oancea, A., . . Wilde, S. (2009). Education for All: The Future of Education and Training for 14-19 Year-Olds. Abingdon: Routledge.

QCA. (2000). Key Skills Standards. London: Qualification and Curriculum Authority. 
QCA. (2007). Functional Skills Standards. London: Qualfications and Curriculum Authority.

Roberts, C., Gidley, N., Eldred, J., Brittan, J., Grief, S., Cooper, B., . . Castillino, C. (2005). Embedded teaching and learning of adult literacy, numeracy and ESOL: Seven case studies. Leicester: NIACE.

Smith, A. (2004). Making Mathematics Count. London: HMSO.

Tomlinson, M. (2004). 14-19 curriculum and qualifications reform: interim report of the working group on 14-19 reform. London: HMSO.

Turner, G., Harkin, I., \& Dawn, T. (2000). Teaching Young Adults: A Handbook for Teachers in Further Education. Florence, KY: Routledge.

Volmink, J. (1994). Mathematics by all. In S. Lerman (Ed.), Cultural perspectives on the mathematics classroom (pp. 51-67). Dordrecht: Kluwer Academic

Wake, G. (2005). Functional mathematics: More than "back to basics". Nuffield Review of 14-19 Education and Training. Aims, Learning and Curriculum Series, Discussion Paper, 17, 1-11.

Wolf, A. (2011). Review of vocational education (DfEE Ed.). London: Department for Education.

Young, M. (1998). The Curriculum of the Future: from the 'new sociology of education' to a critical theory of learning. London: Falmer.

Young, M. (2011). The return to subjects: A sociological perspective on the UK coalition government's approach to the 14-19 curriculum. Curriculum Journal, $22(2), 265-278$. 